\title{
Cobre antimicrobiano contra patógenos intrahospitalarios en Perú
}

\section{Antimicrobial copper against nosocomial pathogens in Peru}

\author{
Edwin Neciosup ${ }^{1, a}$, Martha Vergara ${ }^{1, a}$, Omar Pairazamán ${ }^{2, b}$, Marcos Apablaza $^{2, c}$, \\ Mario Esparza ${ }^{2, b}$ \\ 'Universidad Nacional Pedro Ruiz Gallo, Lambayeque, Perú. \\ ${ }^{2}$ Laboratorio de Biominería, Departamento de Biotecnología, Facultad de Ciencias del Mar y Recursos Biológicos, Universidad de \\ Antofagasta, Antofagasta, Chile. \\ a Biólogo; ${ }^{b}$ Doctor en Microbiología; ${ }^{\circ}$ Bioquímico.
}

\begin{abstract}
Resumen
Introducción: Las infecciones intrahospitalarias (IIH) constituyen un problema de salud pública que generan grandes gastos por parte de los gobiernos, debido a que los patógenos causantes de $\mathrm{IIH}$ presentan resistencia a fármacos y generan una mayor permanencia de los pacientes, pues la infraestructura hospitalaria constituye un reservorio favorable para los patógenos. Las superficies de cobre surgen como opción sanitaria y efectiva para controlar el crecimiento y propagación de estos patógenos. Objetivos: Evaluar la actividad bactericida de las superficies de cobre contra los principales bacterias patógenas causantes de IIH (Escherichia coli, Pseudomonas aeruginosa y Staphylococcus aureus). Diseño: Estudio experimental con muestreo no probabilístico. Lugar: Hospital Regional Docente las Mercedes (HRDLM) y Hospital Provincial Docente Belén (HPDB), Lambayeque, Perú. Materiales: Nueve cepas bacterianas, 3 de E. coli, 3 de $P$. aeruginosa y 3 de $S$. aureus; superficies metálicas $\left(1 \mathrm{~cm}^{2}\right)$ de cobre y acero inoxidable (control). Intervenciones: Las 9 cepas bacterianas fueron proporcionadas por los hospitales HRDLM (4 cepas) y HPDB (5 cepas). Los análisis de ANOVA y de Tukey fueron aplicados para evaluar la actividad bactericida de las superficies de cobre y acero inoxidable contra las 9 cepas causantes de $\mathrm{IH}$, usando los programas estadísticos Minitab y Sigmaplot, respectivamente. Principales medidas de resultados: Diferencias en el crecimiento bacteriano sobre superficies de cobre o acero inoxidable, con respecto al tiempo de exposición. Resultados: Las 9 cepas -3 de $P$. aeruginosa, 3 de E. coli y 3 de $S$. aureus- expuestas a superficies de cobre fueron eliminadas en 10, 15 y 60 minutos, respectivamente. La carga bacteriana de las células expuestas en superficies de acero inoxidable permaneció constante y viable por periodos mayores a 60 minutos. Además, las superficies de cobre eliminaron más rápido a las bacterias Gram negativas $(P$. aeruginosa y E. coli) con respecto a las Gram positivas (S. aureus). Conclusiones: Las superficies de cobre eliminaron totalmente las bacterias intrahospitalarias E. coli, P. aeruginosa y $S$. aureus, a diferencia de las superficies de acero inoxidable, en las que permanecieron viables. De acuerdo a estos resultados, el cobre puede reemplazar al acero inoxidable como superficie de contacto en los centros de salud con incidencia de infecciones intrahospitalarias.
\end{abstract}

Palabras clave: Superficies de cobre, bactericida, infecciones intrahospitalarias.

\section{Abstract}

Introduction: Nosocomial infections (NI) generate large expenditures by governments, as NI pathogens are resistant to drugs and increase hospital stay. Copper surfaces seem a promising alternative to control growth and spread of these pathogens. Objectives: To evaluate copper surfaces bactericidal activity against pathogenic bacteria causing $\mathrm{NI}$ (E. coli, P. aeruginosa and S. aureus). Design: Experimental study with non-probability sampling. Institutions: Hospital Regional Docente las Mercedes (HRDLM) and Hospital Provincial Docente Belen (HPDB), Lambayeque, Peru. Materials: Nine bacterial strains of E. coli, P. aeruginosa and S. aureus, metal surfaces ( $1 \mathrm{~cm} 2$ ) of copper and stainless steel (control). Interventions: Bacterial strains were provided by HRDLM (4 strains) and HPDB (5 strains). ANOVA and Tukey analysis were applied to evaluate copper and stainless steel surfaces' bactericidal activity to strains causing Nl; Minitab statistical software and Sigmaplot were used. Main outcome measures: Differences in bacterial growth on metal surfaces (copper or stainless steel) with respect to exposure time. Results: The nine strains of P. aeruginosa (3), E. coli (3) and S. aureus (3) exposed to copper surfaces were inactivated after 10,15, and 60 minutes respectively. The bacterial load of cells exposed to stainless steel surfaces remained constant and viable for periods longer than 60 minutes. Copper surfaces removed Gram-negative bacteria (E. coli and P. aeruginosa) faster than Gram-positive bacteria (S. aureus). Conclusions: Copper surfaces completely eliminated studied nosocomial bacteria. Thus they could replace steel as contact surfaces in Peruvian health facilities with high incidence of NI.

Keywords: Bactericide copper, copper surfaces, nosocomial infections.

An Fac med. 2015;76(1):9-13 / doi:10.15381/anales.v76i1.11069 


\section{INTRODUCCIÓN}

Las superficies duras que existen en la mayoría de hospitales, tales como pisos, rieles de cama, mesa de noche y manijas de puertas, que generalmente están en contacto constante con los pacientes y el personal de salud, ayudan a la propagación de microorganismos ${ }^{(1-3)}$. Recientemente se ha descrito que las superficies blandas contaminadas, tales como sábanas, pijamas, cortinas, mandiles, cubre almohadas, actúan como reservorio y fuentes de patógenos que pueden contaminar directamente a pacientes y al personal del hospital ${ }^{(4)}$.

Se han aplicado diversas medidas para reducir el riesgo de transmisión de patógenos, que incluyen mejorar la vigilancia de las infecciones nosocomiales, uso de antibióticos agresivos para reducir la expansión de cepas resistentes a antibióticos, capacitaciones al personal de salud para mejorar la higiene y aislamiento de pacientes infectados; estas estrategias implican inversiones continuas por parte del Estado. Sin embargo, el impacto es mínimo sobre las $\mathrm{IIH}^{(3,5,6)}$.

Los materiales metálicos predominantes en los hospitales son el acero inoxidable y el aluminio. Estos metales no tienen efecto alguno sobre los patógenos y constituyen reservorios o fuentes de propagación por contacto. Tras varios estudios, se demostró que el cobre posee un gran potencial biocida capaz de eliminar a patógenos nosocomiales ${ }^{(7-9)}$, bacterias contaminantes de la industria alimentaria ${ }^{(10)}$, virus ${ }^{(4)}$ y hongos ${ }^{(8)}$. Actualmente, existe un gran interés en el uso del cobre como material antimicrobiano. Se estableció el término contact killing (muerte por contacto) debido a la rapidez con la que elimina a una bacteria ${ }^{(11)}$. La no existencia de un mecanismo claro de acción (11) ha llevado a la elaboración de un modelo tentativo, en el cual la bacteria al entrar en contacto con la superficie disuelve el cobre en concentraciones muy pequeñas, lo que condiciona el inicio del daño celular ${ }^{(12)}$. Posteriormente, la membrana celular se rompe debido al cobre y por fenómenos de estrés -lo que produce la pérdida del potencial de membrana y el vertido del contenido citoplasmático-, los iones de cobre inducen la generación de especies reactivas de oxigeno (ROS) ${ }^{(13)}$ que aumentan el daño celular producido ${ }^{(11,12)}$, y el ADN genómico y plasmidial comienza a ser degradado ${ }^{(12)}$.

Las superficies de cobre con sus propiedades antimicrobianas y su fácil implementación en hospitales y centros de salud pueden ser una importante contribución al control de las infecciones, que implicaría la reducción del hacinamiento de pacientes en tratamiento, la diseminación de patógenos vía aérea o por contacto, así como el uso de fármacos a los que gran variedad de patógenos han adquirido resistencia. Esto se ha demostrado recientemente en ensayos hospitalarios exitosos en países como Estados Unidos ${ }^{(14)}$, Reino Unido ${ }^{(7,15)}$, Sudáfrica ${ }^{(8)}$, Suiza ${ }^{(16)}$ y Chile ${ }^{(9)}$. Sin embargo, en el Perú no existe evidencia científica que compruebe la propiedad antimicrobiana del cobre frente a las principales bacterias patógenas causantes de $\mathrm{IIH}$, como E. coli, P. aeruginosa y S. aureus.

\section{MÉTODOS}

Se evaluó nueve cepas - 3 de E. coli, 3 de S. aureus y 3 de P. aeruginosa, pro-

Tabla 1. Características de las cepas bacterianas causantes de infecciones intrahospitalarias (IIH) usadas en este estudio.

\begin{tabular}{|c|c|c|c|c|}
\hline Cepa & Abreviatura & Procedencia & IIH asociada & Respuesta al Gram \\
\hline \multirow{3}{*}{ E. coli } & Ecol1 & HRDLM & bacteremia & Negativa \\
\hline & Ecol2 & HPDB & infección urinaria & Negativa \\
\hline & Ecol3 & HPDB & infección urinaria & Negativa \\
\hline \multirow{3}{*}{ P. aeruginosa } & Paer1 & HRDLM & neumonía & Negativa \\
\hline & Paer2 & HRDLM & infección de la piel & Negativa \\
\hline & Paer3 & HPDB & infección de la piel & Negativa \\
\hline \multirow{3}{*}{ S. aureus } & Saur1 & HRDLM & infección urinaria & Positivo \\
\hline & Saur2 & HPDB & infección a la piel & Positivo \\
\hline & Saur3 & HPDB & infección a la piel & Positivo \\
\hline
\end{tabular}

HRDLM: Unidad de Cuidados intensivos del Hospital Regional Docente "Las Mercedes", Chiclayo. HPDB: Hospital Provincial Docente "Belén" (HPDB), Lambayeque. cedentes de la unidad de cuidados intensivos del Hospital Regional Docente "Las Mercedes" (HRDLM), Chiclayo, y del Hospital Provincial Docente "Belén” (HPDB), Lambayeque. Todas las cepas fueron aisladas en agar sangre e identificadas bioquímicamente en el laboratorio (tabla 1).

Las láminas de cobre y acero inoxidable fueron obtenidas comercialmente.

Para el experimento, las nueve cepas bacterianas fueron sembradas e incubadas independientemente en agar TSA (Merck) ${ }^{(9)}$, selladas herméticamente y almacenadas en refrigeración a $4^{\circ} \mathrm{C}$.

Para la evaluación de la actividad bactericida de las superficies de cobre, se siguió el modelo ${ }^{(7)}$ modificado, el cual se describe a continuación.

Las láminas de cobre C11000 proporcionado por Storm Copper y acero inoxidable (JN aceros) fueron cortadas en tamaños de $1 \mathrm{~cm}^{2}$. Nueve láminas para cada metal fueron envueltas en papel y esterilizadas en autoclave por 1 hora, luego sumergidas en etanol (Merck) al 95\% y flameadas al mechero por 2 segundos; después fueron transferidas a placas Petri estériles.

Los viales conteniendo las nueve cepas bacterianas, se retiraron de refrigeración a temperatura ambiente durante 5 minutos. Luego una colonia de cada 
cepa se transfirió a $2 \mathrm{~mL}$ de caldo nutritivo e incubó a $37^{\circ} \mathrm{C}$ por 16 horas. Los cultivos bacterianos resultantes se diluyeron con agua destilada estéril hasta alcanzar $\sim 2 \times 10^{7} \mathrm{UFC} / \mathrm{mL}$ de acuerdo al tubo número 0,5 del nefelómetro de Mac Farland ${ }^{(9)}$.

En cada lámina de cobre y acero inoxidable se inoculó $10 \mu \mathrm{L}$ de las suspensiones bacterianas ( $2 \times 10^{7} \mathrm{UFC} /$ $\mathrm{mL})$. Cada inóculo fue distribuido sobre el metal con una punta estéril de $10 \mu \mathrm{L}$. Se incubó las láminas metálicas por triplicado a temperatura ambiente, a diferentes tiempos de exposición $\left(t_{0}=\right.$ $0 \min , \mathrm{t}_{1}=5 \mathrm{~min}, \mathrm{t}_{2}=10 \mathrm{~min}, \mathrm{t}_{3}=15$ $\min , \mathrm{t}_{4}=20 \mathrm{~min}, \mathrm{t}_{5}=30 \mathrm{~min}, \mathrm{t}_{6}=45$ $\min , \mathrm{t}_{7}=60 \mathrm{~min}, \mathrm{t}=75 \mathrm{~min}$ ).

Para retirar las bacterias de la superficie metálica se procedió con un lavado, sumergiendo el metal con el inóculo dentro de un tubo estéril con $1 \mathrm{~mL}$ de solución salina fisiológica. Después, se agitó por un minuto y se retiró el metal. Posteriormente, la suspensión celular resultante fue sometida a las siguientes diluciones: $10^{-1}, 10^{-2}, 10^{-3}$ y $10^{-4}$. Luego, $10 \mu \mathrm{L}$ de la dilución $10^{-4}$ fueron sembrados en placa por la técnica de la microgota ${ }^{(8)}$ y se incubó a $36^{\circ} \mathrm{C}$ por 24 horas. Este procedimiento se siguió para todos los tiempos de exposición.

El tiempo necesario para que las superficies de cobre eliminaran a las cepas en estudio fue determinado por triplicado, considerándose cuando no se encontró crecimiento de bacterias en los cultivos. El rango de exposición fue de 75 minutos, seccionados en 9 tiempos.

Para el análisis estadístico, los resultados obtenidos para la actividad de las superficies de cobre fueron comparados con el control de acero inoxidable y con la formación de CFU/mL de las cepas en estudio. La significancia se obtuvo mediante el análisis de ANOVA de una vía utilizando el software MINITAB. Posteriormente, se realizó una prueba de Tuckey $(\mathrm{p}<0,05)$, para establecer el grupo determinado de estas diferencias mediante la utilización del software Sigma plot versión 13.

\section{RESULTADOS}

Para determinar la actividad bactericida de las superficies de cobre sobre las cepas de estudio (tabla 1), se utilizó como control láminas de acero inoxidable.

El análisis de varianza ANOVA permitió determinar que existieron diferencias significativas entre el crecimiento de las cepas en estudio $\left(\mathrm{F}_{8,162}=107,34\right.$; $\mathrm{P}<0,05)$ y los distintos tiempos de exposición al cobre y al acero inoxidable: $t_{0}=0 \mathrm{~min}, \mathrm{t}_{1}=5 \mathrm{~min}, \mathrm{t}_{2}=10$ $\min , t_{3}=15 \mathrm{~min}, t_{4}=20 \mathrm{~min}, t_{5}=30$ $\min , \mathrm{t}_{6}=45 \mathrm{~min}, \mathrm{t}_{7}=60 \min \mathrm{y}_{8}=75$ $\min \left(\mathrm{F}_{8,162}=892,14 ; \mathrm{P}<0,05\right)$. Para encontrar dónde se hallaban estas significancias, se aplicó el análisis Tuckey, determinando que existen diferencias significativas en: $\left(1^{\mathrm{o}}\right)$ en dos cepas de E. coli, Ecol1 y Ecol2 $(\mathrm{P}<0,05)$, para el $\mathrm{t}_{0}=0 \mathrm{~min} ;\left(2^{\mathrm{o}}\right)$ en $\mathrm{t}_{0}=0 \mathrm{~min}$ entre las cepas de $E$. coli con respecto a las cepas de $P$. aeruginosa $(\mathrm{P}<0,05) ;\left(3^{\circ}\right)$ entre la comparación de E. coli con las cepas de S. aureus para los tiempos: $t_{1}=5 \mathrm{~min}$, $\mathrm{t}_{2}=10 \mathrm{~min}, \mathrm{t}_{3}=15 \mathrm{~min} \mathrm{t}_{4}=20 \mathrm{~min} \mathrm{y}$ el tiempo $t_{0}=0 \mathrm{~min}$, solo en Ecoll y en Saur3 $(\mathrm{P}<0,05)$; $\left(4^{\mathrm{O}}\right)$ entre los tiempos $\mathrm{t}_{1}=5 \mathrm{~min}, \mathrm{t}_{2}=10 \mathrm{~min}, \mathrm{t}_{3}=15 \mathrm{~min} \mathrm{y}$ $\mathrm{t}_{4}=20$ min para $P$. aeruginosa y S. aureus $(\mathrm{P}<0,05)$. Finalmente, entre los demás tiempos de exposición y el crecimiento microbiano no se encontró diferencias significativas $(\mathrm{P}>0,05)$.

Todas las cepas evaluadas fueron eliminadas en una hora en presencia de la lámina de cobre; además, el número de bacterias viables se redujo conforme aumentaba el tiempo de exposición. Por otro lado, en la superficie de acero inoxidable, todas las bacterias permanecieron viables después de su inoculación, incluso sin reducción en el número de células.

En la figura 1 se observa el crecimiento de las cepas de E. coli-Ecol1, Ecol2 y Ecol3-, demostrando que las superficies de cobre eliminaron un número de $2 \times 10^{7} \mathrm{UFC} / \mathrm{mL}$ en $15 \mathrm{~min}$ en las tres cepas. Resultados similares se muestran con la exposición de las tres cepas de P. aeruginosa: Paer1, Paer2 y Paer3 a las superficies de cobre; aquí se observó una eliminación rápida del número de bacterias iniciales, en un tiempo aproximado de 10 minutos (figura 2). Considerando los resultados para las tres cepas de S. aureus, estos difieren

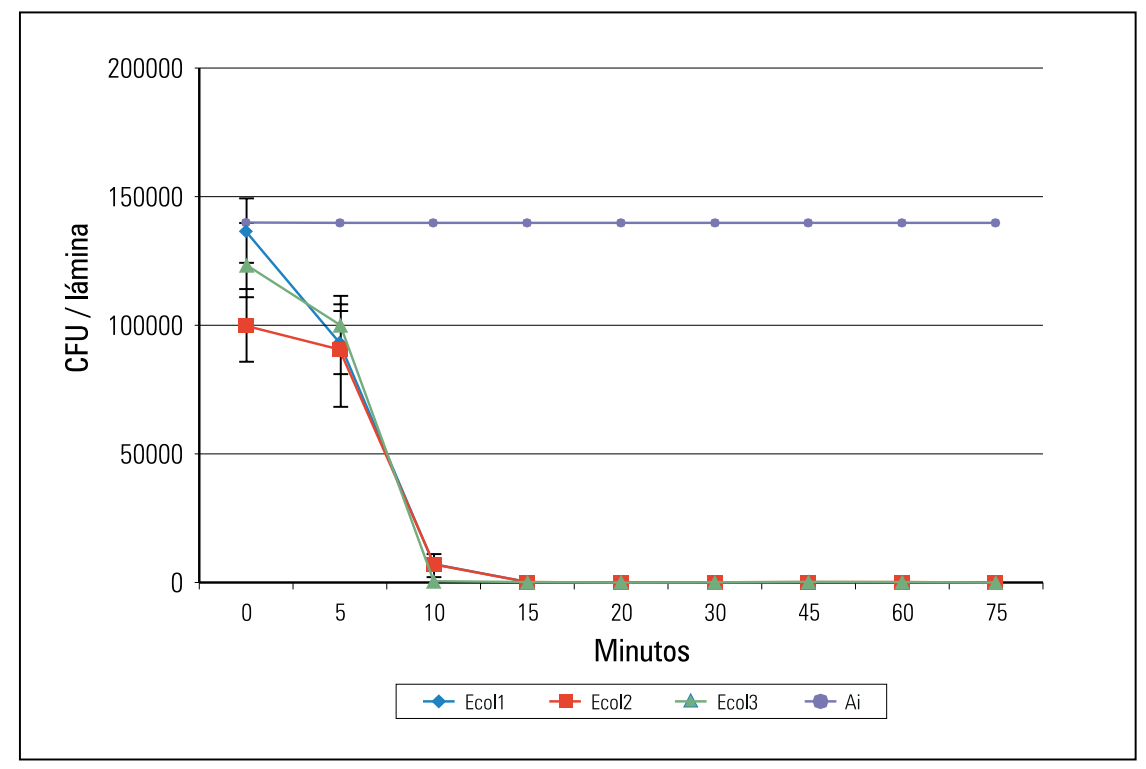

Figura 1. Curva de muerte para las cepas de Escherichia coli (aislamientos clínicos a temperatura ambiente). Recuentos de colonias crecidas en medio de cultivo sólido TSA, después de ser expuestos a las láminas de cobre de las cepas: Ecol1 ( $\bullet$ ), Ecol2 ( $\square$ ) y Ecol3 ( $\Delta$ ) y acero inoxidable (Ai $x)$, con un inóculo inicial de 2-3 $\times 10^{7} \mathrm{UFC} / \mathrm{mL}$. 


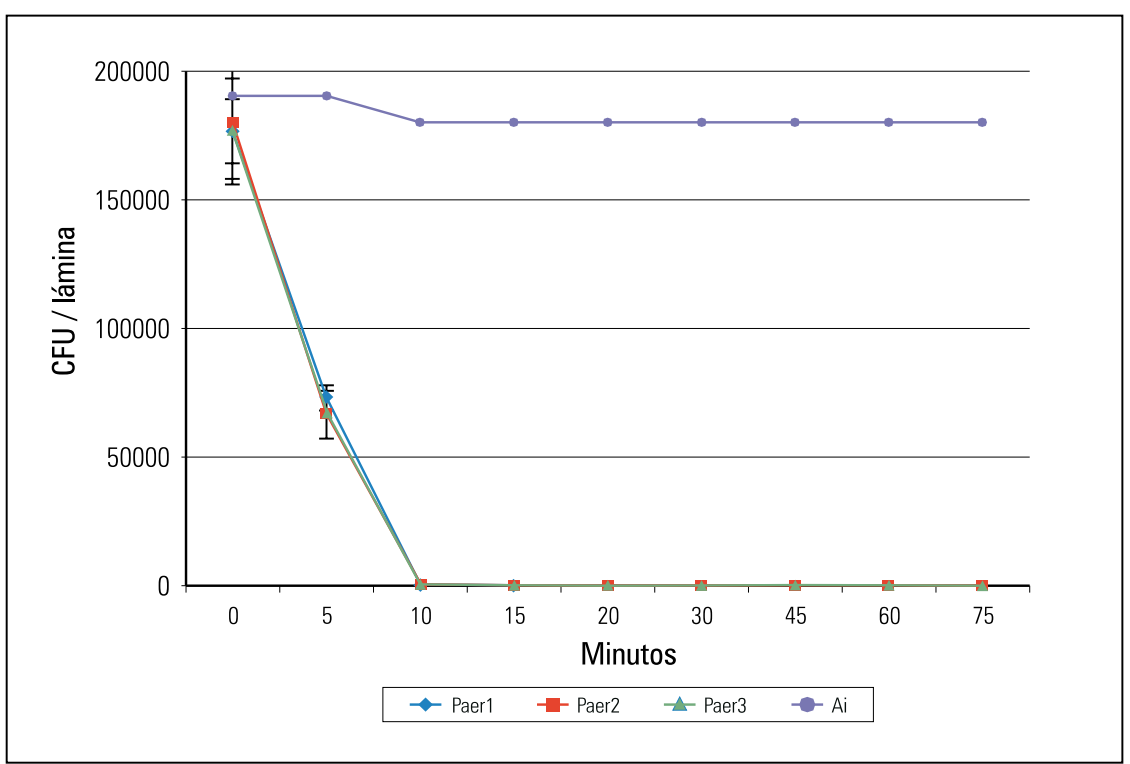

Figura 2. Curva de muerte para las cepas de Pseudomonas aeruginosa (aislamientos clínicos a temperatura ambiente). Recuentos de colonias crecidas en medio de cultivo sólido TSA, después de ser expuestos a las láminas de cobre de las cepas: Paer1 $(\star)$, Paer2 ( $\square$ ) y Paer3 $(\Delta)$ y acero inoxidable (Ai x), con un inóculo inicial de 2-3 x $10^{7} \mathrm{UFC} / \mathrm{mL}$.

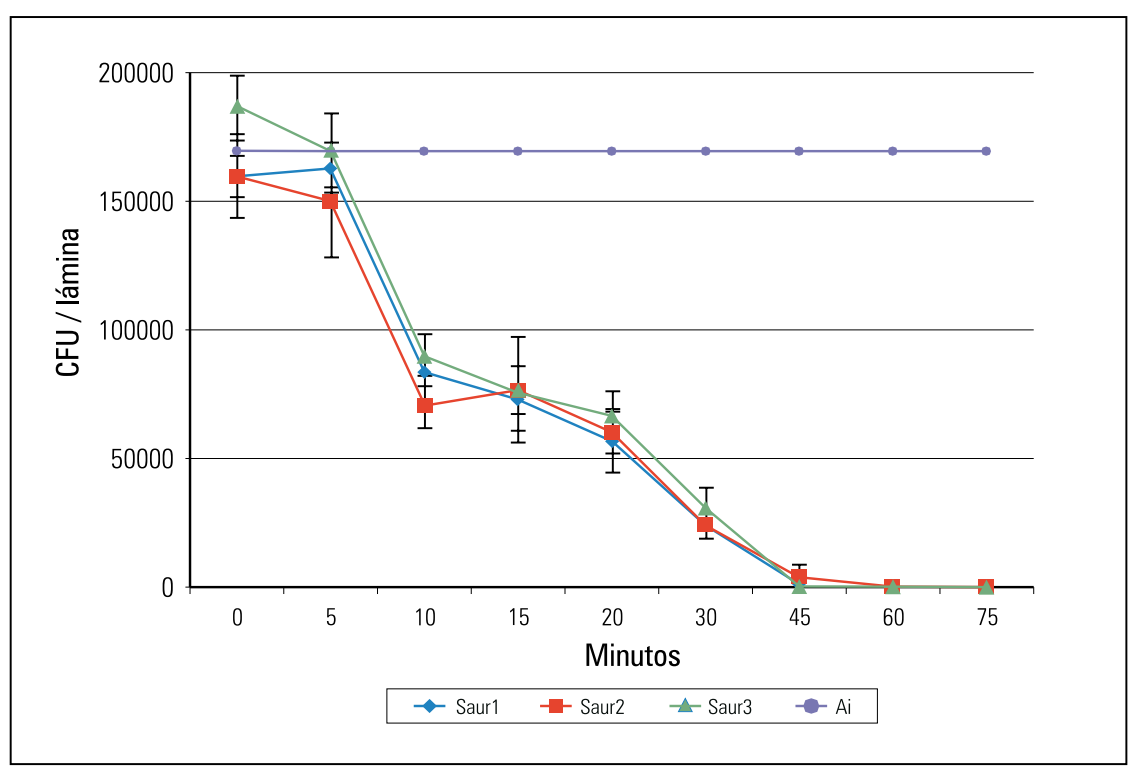

Figura 3. Curva de muerte para las cepas de Staphylococcus aureus (aislamientos clínicos a temperatura ambiente). Recuentos de colonias crecidas en medio de cultivo sólido TSA, después de ser expuestos a las láminas de cobre de las cepas: Saur1 $(\bullet)$, Saur2 $(\square)$ y Saur3 $(\boldsymbol{\Delta})$ y acero

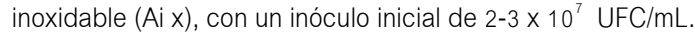

mucho a los obtenidos con las dos especies anteriormente mencionadas. Su exposición a superficies de cobre mostró una eliminación completa en $60 \mathrm{mi}$ nutos; además, es posible apreciar una mayor resistencia de Saur3 y en menor grado Saur1 y Saur2 (figura 3).
Según los promedios de muerte bacteriana por el tiempo, se determinó que para eliminar las cepas de P. aeruginosa, E. coli y S. aureus son necesarios como mínimo 10, 15 y 60 minutos de exposición, respectivamente, a las láminas de cobre.

\section{DISCUSIÓN}

El acero inoxidable es ampliamente utilizado en los establecimientos de salud por sus costos, facilidad de limpieza y su resistencia a la corrosión. Sin embargo, en este y otros trabajos se demuestra que los patógenos asociados a infecciones intrahospitalarias permanecen viables por largos periodos de tiempo sobre las superficies de acero inoxidable, constituyendo un potencial reservorio de microorganismos patógenos ${ }^{(1,2,17)}$, entre los cuales se encuentran E. coli, P. aeruginosa y S. aureus.

Con respecto a otros estudios del efecto de las superficies de cobre sobre estas bacterias, se conoce los siguientes tiempos de supervivencia: E. coli de 30 a $60 \mathrm{~min}{ }^{(11)}$, P. aeruginosa, de $180 \mathrm{~min}^{(8)}$ y S. aureus muere entre 60 y $180 \mathrm{~min}^{(7)}$. En cambio, los resultados obtenidos por este estudio indican que las cepas de $E$. coli Ecol1, Ecol2 y Ecol3 poseen tiempos semejantes de eliminación, ocurridas entre los 10 a 15 minutos, con una eliminación completa ocurrida a los 15 minutos (figura 1).

Las cepas de $P$. aeruginosa, en cambio, fueron eliminadas completamente a los 10 minutos, presentando Paer1, Paer2 y Paer3 un comportamiento similar (figura 2). En consecuencia, la rápida eliminación de ambas bacterias Gram negativas se debe a la interacción directa de la membrana celular externa con la superficie de cobre; en cambio, para las cepas de $S$. aureus gram positivas Saur1, Saur2 y Saur3, se puede observar un tiempo de eliminación más lento y gradual, ocurrido totalmente a los 60 minutos.

Un hallazgo interesante de nuestro trabajo fue que las cepas de S. aureus tienen un mayor tiempo de supervivencia a las superficies de cobre que las cepas de E. coli y de P. aeruginosa, lo que contradice los reportes mostrados por otros autores ${ }^{(7,8,14)}$. Posiblemente, su pared celular evitaría el daño oxidativo temprano de la membrana. Se sugiere que la envoltura de las bacterias no es un buen indicador del daño provocado por el contacto con las superficies de 
cobre, pues las bacterias Gram positivas y negativas responden de la misma forma ${ }^{(18)}$. Pero, en este trabajo demostramos que existe un efecto diferenciado entre el efecto de las superficies del cobre con las bacterias Gram positivas y las Gram negativas, posiblemente debido a la estructura de la pared celular bacteriana.

En ambientes hospitalarios, la carga bacteriana es aproximadamente $6 \times 10^{3}$ $\mathrm{UFC} / \mathrm{cm}^{2}{ }^{(19)}$, muy similar a la carga microbiana empleada en este trabajo, condición que nos permitió evidenciar in vitro el mecanismo bactericida de las superficies de cobre de manera análoga a lo que ocurre en un hospital. Futuras investigaciones pueden abordar la carga microbiana del personal médico y evaluar su efecto a las superficies de cobre.

Actualmente, ninguna bacteria resistente a superficies de cobre ha sido descrita. El motivo por el cual no se ha generado resistencia a las superficies de cobre es por su mecanismo de acción ${ }^{(19)}$ e incluso bacterias sensibles y resistentes a los antibióticos como también bacterias con una tasa de reparación elevada de ADN fueron eliminadas mucho más rápido que otras bacterias que carecen de dicha capacidad ${ }^{(8,18,16)}$. Posiblemente estos mecanismos independientes o en conjunto sustentan la sensibilidad de las bacterias empleadas en este trabajo (figuras 1,2 y 3), y en consecuencia el cobre surge como un metal candidato para ser implementado en ambientes hospitalarios en lugar del acero inoxidable, el cual sigue siendo un reservorio de patógenos.

En conclusión, esta investigación aporta al conocimiento y confirma la actividad bactericida de las superficies de cobre, a diferencia del acero inoxidable frente a patógenos nosocomiales, y proponemos el uso del cobre metálico o aleaciones del mismo como material alternativo para el control de los patógenos y disminuir las IIH.

\section{AGRADECIMIENTO}

A José Niño Valiente, Jefe del área de Microbiología del Hospital Provincial Docente Belén, Lambayeque, por proporcionar los aislamientos bacterianos requeridos para el estudio.

\section{REFERENCIAS BIBLIGRÁFICAS}

1. Kramer A, Schwebke I, Kampf G. How long do nosocomial pathogens persist on inanimate surfaces? A systematic review. BMC Infect Dis. 2006;6:130-8. Doi: 10.1186/1471-2334-6-130.

2. Bhalla A, Pultz N, Gries D, Ray A, Eckstein E, Aron $D$, Donskey C. Acquisition of nosocomial pathogens on hands after contact with environmental surfaces near hospitalized patients. Infect Control Hosp. 2004;25(2):164-7.

3. Vargas R. Exceso de costos por sepsis intrahospitalaria en dos servicios de neonatologia de Trujillo, Perú 2003-2005. Rev Med Exp Salud Publica. 2008;25(2):185-9.

4. Borkow G, Gabbay J. Biocidal textiles can help fight nosocomial infections. Med Hypothesis. 2008;70(5):990-4.

5. Cuellar P, Rosales L, Aquiño F. Eficacia de un proGrama educativo para la prevención y el control de infecciones intrahospitalarias en el instituto especializado de enfermedades neoplásicas, Lima, Perú. Rev Med Exp Salud Publica. 2004;21(1):37-43.

6. Arévalo $H$, Cruz R, Palomino F, Fernández $F$, Guzmán E, Melgar R. Aplicación de un proGrama de control de infecciones Intrahospitalarias en establecimientos de salud de la región San Martin, Perú. Rev Med Exp Salud Publica. 2003;20(2):84-91.

7. Noyce J, Michels H, Keevil C. Potential use of cooper surfaces to reduce survival of epidemic meticilin-resistant Staphylococcus aureus in the healthcare environment. J Hosp Infect. 2006;63(3):289-97.

8. Methar S, Wiid I, Todorov S. The antimicrobial activity of copper and copper alloys against nosocomial pathogens and Mycobacterium tuberculosis isolated from healthcare facilities in the Western Cape: an in-vitro study. J Hosp Infect. 2008;68(1):45-51.

9. Prado V, Esparza M, Vidal R, Duran C. Actividad bactericida de superficies de cobre frente a bacterias asociadas a infecciones nosocomiales, en un modelo in vitro de adherencia y sobrevivencia. Rev Med Chile. 2013;141:291-7. doi: 10.4067/ S0034-98872013000300002.
10. Faúndez G, Troncoso M, Navarrete P, Figueroa G. Antimicrobial activity of copper surfaces against suspensions of Salmonella enterica and Campylobacter jejuni. BMC Microbiol. 2004;(4):19. doi: 10.1186/1471-2180-4-19.

11. Grass G, Rensing C, Solioz M. Metallic copper as an antimicrobial surface. Appl Environ Microbiol. 2011;77(5):1541-7. doi: 10.1128/AEM.02766-10.

12. Borkow G, Gabbay J. Copper as a biocidal tool. Curr Med Chem. 2005;12(18):2163-75.

13. Kozlowski H, Kolkowska P, Watly J, Krywoszynska K, Potocki S. General aspects of metal toxicity. Curr Med Chem. 2014;21(33):3721-40.

14. Michels H, Noyce J, Keevil C. Effects of temperature and humidity on the efficacy of methicillinresistant Staphylococcus aureus challenged antimicrobial materials containing silver and copper. Appl1 Microbiology. 2009;49(2):191-5. doi: 10.1111/j.1472-765X.2009.02637.x.

15. Casey D, Adams D, Karpanen T, Lambert P, Cookson B, Nightingale P, Miruszenko L, Shillam $\mathrm{R}$, Christian P, Elliot T. Role of copper in reducing hospital environment contamination. J Hosp Infect. 2010;74:72-7. doi: 10.1016/j.jhin.2009.08.018.

16. Molteni $\mathrm{C}$, Abicht $\mathrm{H}$, Solioz M. Killing of bacteria by cooper surfaces involves dissolved copper. Appl Environ Microbiol. 2010;76(12):4099-101. doi: 10.1128/AEM.00424-10.

17. Hota B. Contamination, disinfection, and cross-colonization: are hospital surfaces reservoirs for nosocomial infection? Clin Infect Dis. 2004;39(8):1182-9.

18. Santo E, Lam E, Elowsky C, Quaranta D, Domaille D, Chang C, Grass G. Bacterial killing by dry metallic copper surfaces. Appl Environ Microbiol. 2011;77(3):794-802. doi: 10.1128/AEM.01599-10.

19. Oie S, Hosokawa I, Kamiya A. Contamination of room door handles by methicillin-sensitive/ methicillin-resistant Staphylococcus aureus. J Hosp Infection. 2002;51(2):140-3.

Artículo recibido el 25 de mayo de 2014 y aceptado para publicación el 11 de octubre de 2014.

Fuentes de financiamiento: Cofinanciado por fondo Ideas Innovativas UA y por los autores.

Conflictos de interés: Los autores señalan no tener conflictos de interés.

Correspondencia:

Dr. Mario Esparza

Dirección: Laboratorio de Biominería, Dpto. de Biotecnología, Facultad de Ciencias del Mar y Recursos Biológicos, Universidad de Antofagasta, Av. Angamos 601, Antofagasta, Chile

Teléfono: 056-055-2637445 / 056-9-85237572 Correo electrónico: mrodrigount@yahoo.com 